\title{
A new ZVT multi input converter for hybrid sources systems
}

\author{
Majid Delshad ${ }^{1}$, Amir Torki Harchegani ${ }^{2}$, Mojtaba Karimi ${ }^{3}$, Mohammad Mahdavi ${ }^{4}$ \\ Dept. of electrical engineering, Isfahan (Khorasgan) Branch, Islamic Azad University \\ Isfahan, Iran \\ 1.delshad.majid@gmail.com \\ 2. amirth.1991@yahoo.com \\ 3.mog101024@gmail.com \\ 4.mu.mahdavi@gmail.com
}

\begin{abstract}
Renewable energy sources such as wind and solar energy sources are unreliable in different weather conditions to provide constant output voltage. So the concurrent use of different input sources is inevitable to provide a constant load. The use of a Multi-Input Converters (MICs) instead of several separate converters can reduce the number of passive elements. Also it can save the cost and reduce the weight and the volume of the converter. In this paper, a Zero Voltage Transition (ZVT) dual input boost converter is proposed. In addition to the mentioned advantages for the multi-input converters, in the proposed converter only one auxiliary circuit is used for providing soft switching condition for all semiconductor elements and increasing the efficiency. The proposed converter theoretically is analyzed. Then, in order to show the validity of theoretical analysis, it is simulated by ORCAD. The simulation results confirmed the theoretical analysis. The efficiency comparison shows one percent improvement in comparison with hard switching counterpart.
\end{abstract}

Keywords-Hybrid Power Supply, Multi Input Converter (MIC), Zero Voltage Switching, ZVT

\section{INTRODUCTION}

Global warming and fuel crisis are important factors for more attention in renewable energy sources [1]-[3]. Wind and photovoltaic energy have capability to supply demand energy in distant places or out of grid and even in densely populated areas. Since the power produced in renewable energy sources are dependent on environmental conditions such as climate and different seasons, concurrent use with other sources is inevitable to ensure the proper operation.

Several independent converters or a multi input converter can be used to supply the load from several distinct sources. The idea of multi input converters originated from combination of independent converters to make high power converters [4],[5]. By using a multi input converter, the cost of semiconductor and passive elements is reduced. For example, one output filter can be used for several converters. Therefore, it reduces the size and increases the efficiency of the converter. Also another advantage of MICs is possibility of easier control, higher flexibility and better management in energy sources.

MICs divide into two categories including Magnetically Coupled Converter (MCC) and Electrically Coupled Converter (ECC) [6]-[10]. ECCs have the advantages such as high reliability and easier control in variable input Compared to the MCCs But, they have the disadvantages like non-isolation between input and output and non-multilevel output.

Generally, the main purposes of designer are improving efficiency, reliability and reducing the cost of system. Therefore, different topologies for MICs have been proposed in recent years. To achieve above objectives, soft switching technique has been used. Because it can reduce the switching losses and Electromagnetic Interference (EMI) [11],[12].

In [13],[14] tried to provide soft switching and increase the efficiency condition for all of switches simultaneously only by adding one auxiliary circuit. But the main problem of presented topologies in these references are that only soft switching condition is provided for main switches and soft switching condition is not provided for auxiliary switch.

In this paper, a multi input converter for simultaneous or independent use of wind or solar energy resources is presented. In that, the proposed converter provided soft switching for all semiconductor elements simultaneously with only one auxiliary circuit.

In the next section, the performance of the proposed converter is investigated theoretically. The proposed converter is designed at 300 watts. Then the converter performance results are compared with theoretical analysis. Finally, section IV presents the conclusions.

\section{PROPOSED CONVERTER}

The proposed dual input converter is shown in the fig. 1. The general structure of the proposed converter consists of two boost converter with one auxiliary cell that provides zero voltage soft switching condition for both converters. The auxiliary circuit is shown in the doted box. The proposed converter can work with one 
source independently or with two input sources simultaneously.

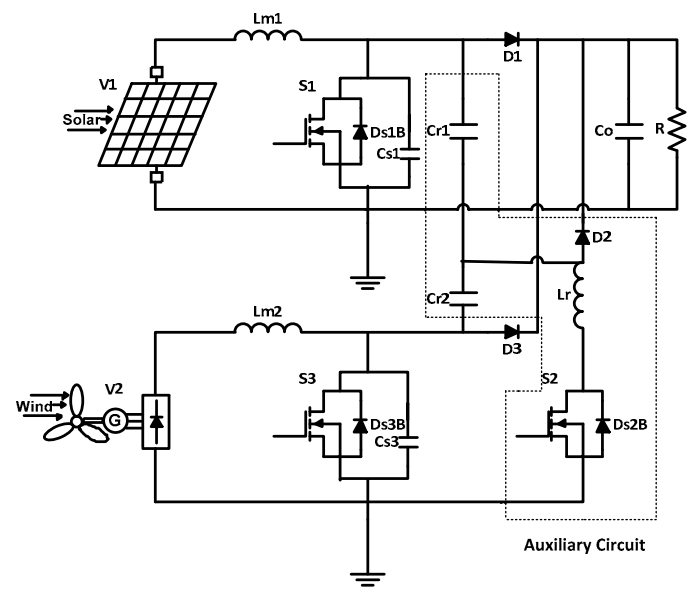

Figure 1. The proposed ZVT dual input converter

In order to analyze the proposed converter in the steady state and during a switching cycle, the following assumptions are made. The output capacitor $\mathrm{C}_{\mathrm{o}}$ and input inductors $\left(\mathrm{L}_{\mathrm{m} 1}, \mathrm{l}_{\mathrm{m} 2}\right)$ are assumed to be large enough so they can be considered an ideal DC voltage and current source respectively. All of the circuit elements are ideal and the converter is operated in continuous Current Mode CCM.

The operation of this circuit is analyzed in ten modes. To control the converter, the two main switches turn on simultaneously, but may turn off asynchronously. Equivalent circuit of each mode is shown in fig. 3. Also in fig. 2 key waveform of the theoretical analysis is shown. Before the first mode, all of the semiconductor devices instead of $\mathrm{D}_{1}$ and $\mathrm{D}_{3}$ are off. Also the voltage of $\mathrm{C}_{\mathrm{r} 1}$ and $\mathrm{C}_{\mathrm{r} 2}$ and current of $\mathrm{L}_{\mathrm{r}}$ are zero.

Mode $1\left[\mathrm{t}_{0}-\mathrm{t}_{1}\right]$ The auxiliary switch $\mathrm{S}_{2}$ turn on at $\mathrm{t}_{0}$ under $\mathrm{ZC}$ condition. A resonance occurs between $\mathrm{L}_{\mathrm{r}}$, $\mathrm{C}_{\mathrm{r} 1}$ and $\mathrm{C}_{\mathrm{r} 2}$. This mode continues until current of $\mathrm{L}_{\mathrm{r}}$ reaches to the output current. The current of $\mathrm{L}_{r}$ and the voltage of $\mathrm{C}_{\mathrm{r}}$ are expressed by the following equations.

$$
\begin{gathered}
\mathrm{I}_{\mathrm{Lr}}=\frac{\mathrm{V}_{0}}{\mathrm{Z}_{1}} \sin \left(\omega_{1}\left(\mathrm{t}-\mathrm{t}_{0}\right)\right) \\
\mathrm{V}_{\mathrm{cr}}(\mathrm{t})=\mathrm{V}_{0}-\mathrm{V}_{0} \cos \left(\omega_{1}\left(\mathrm{t}-\mathrm{t}_{0}\right)\right) \\
\mathrm{Z}_{1}=\sqrt{\frac{\mathrm{L}_{\mathrm{r}}}{\mathrm{C}_{\mathrm{r}}}} \\
\mathrm{C}_{\mathrm{r}}=\mathrm{C}_{\mathrm{r} 1}+\mathrm{C}_{\mathrm{r} 2} \\
\omega_{1}=\frac{1}{\sqrt{\mathrm{L}_{\mathrm{r}} \mathrm{C}_{\mathrm{r}}}}
\end{gathered}
$$

Mode $2\left[\mathrm{t}_{1}-\mathrm{t}_{2}\right]$ At the beginning of this mode, $\mathrm{D}_{1}$ and $\mathrm{D}_{3}$ are turned off under zero current and voltage condition. Then a resonance between $\mathrm{L}_{\mathrm{r}}, \mathrm{C}_{\mathrm{r} 1}, \mathrm{C}_{\mathrm{r} 2}, \mathrm{C}_{\mathrm{S} 1}$ and $\mathrm{C}_{\mathrm{S} 3}$ is started. This state continues until switch voltage is reached to zero.

Mode $3\left[t_{2}-t_{3}\right]$ At the beginning of this mode $C_{s}$ is completely discharged and the body diode $\mathrm{S}_{1}$ and $\mathrm{S}_{3}$ are turned on. Therefore, $S_{1}$ and $S_{3}$ can be turned on under zero voltage zero current (ZVZC) condition. Also $L_{r}$ voltage is equal to $-\mathrm{V}_{\text {cr. }}$. It must be noted that, $\mathrm{S} 1$ and $\mathrm{S} 3$ should be turned on before turning off $\mathrm{D}_{\mathrm{s} 1 \mathrm{~B}}$ and $\mathrm{D}_{\mathrm{s} 3 \mathrm{~B}}$. So, $\mathrm{I}_{\mathrm{Lr}}$ is decreased to $\mathrm{I}_{\mathrm{in}}$. In this mode, growth rate of $\mathrm{I}_{\mathrm{s} 1}$ and $\mathrm{I}_{\mathrm{s} 3}$ is determined by the resonant frequency. $\mathrm{I}_{\mathrm{Lr}}$ and $\mathrm{V}_{\mathrm{Cr}}$ are expressed by the following equations.

$$
\begin{array}{r}
\mathrm{I}_{\mathrm{Lr}}(\mathrm{t})=\mathrm{I}_{2} \cos \left(\varphi\left(\mathrm{t}-\mathrm{t}_{2}\right)\right)-\frac{\mathrm{V}_{2}}{\mathrm{~V}_{1}} \sin \left(\omega\left(\mathrm{t}-\mathrm{t}_{2}\right)\right) \\
\mathrm{V}_{\mathrm{Cr}}(\mathrm{t})=\mathrm{V}_{2} \cos \left(\omega\left(\mathrm{t}-\mathrm{t}_{2}\right)\right)+\mathrm{I}_{2} \mathrm{Z}_{1} \sin \left(\omega\left(\mathrm{t}-\mathrm{t}_{2}\right)\right) \\
\mathrm{I}_{2}=\mathrm{I}_{\mathrm{Lr}}\left(\mathrm{t}_{2}\right)=\sqrt{\frac{\mathrm{L}_{\mathrm{r}} \mathrm{I}_{1, \mathrm{p}}^{2}-\mathrm{C}_{\mathrm{r}} \mathrm{V}_{2}^{2}}{\mathrm{~L}_{\mathrm{r}}}} \\
\mathrm{V}_{2}=\mathrm{V}_{\mathrm{Cr}}\left(\mathrm{t}_{2}\right)=\frac{\mathrm{I}_{\text {in }}}{\mathrm{C}_{\mathrm{r}}}\left(\mathrm{t}_{2}-\mathrm{t}_{1}\right)+\frac{\mathrm{C}_{\mathrm{s}}}{\mathrm{C}_{\mathrm{r}}} \mathrm{V}_{\mathrm{o}}+\mathrm{V}_{\mathrm{Cr}}\left(\mathrm{t}_{1}\right)
\end{array}
$$

Mode $4\left[t_{3}-t_{4}\right]$ When $I_{S 3}$ and $I_{S 1}$ are increased to $I_{\text {in2 }}$ and $\mathrm{I}_{\mathrm{in} 1}$, this mode is started and $\mathrm{D}_{\mathrm{s} 2 \mathrm{~B}}$ is turned on. Therefore, the auxiliary switch $\mathrm{S}_{2}$ can be turned off under ZVZC condition. $\mathrm{I}_{\mathrm{Lr}}$ becomes zero and the $\mathrm{C}_{\mathrm{r}}$ voltage reaches to $V_{\text {cr,P. }} D_{2}$ Voltage stress is equal to $\mathrm{V}_{\mathrm{o}}+\mathrm{V}_{\text {cr,P }}$, which $\mathrm{V}_{\text {cr,P }}$ is shown by (10). Resonance between $C_{r}$ and $L_{r}$ continues through $S_{1}, S_{3}$ and $D_{s 2 B}$. Also, the current spike of turning on main switches expressed by (11).

$$
\begin{array}{r}
\mathrm{V}_{\mathrm{Cr}, \mathrm{p}}=\sqrt{\frac{\mathrm{L}_{\mathrm{r}} \mathrm{I}_{\mathrm{Lr}}\left(\mathrm{t}_{2}\right)^{2}+\mathrm{C}_{\mathrm{r}} \mathrm{V}_{\mathrm{Cr}}\left(\mathrm{t}_{2}\right)^{2}}{\mathrm{C}_{\mathrm{r}}}} \\
\mathrm{I}_{\mathrm{s} 1, \mathrm{p}}=\mathrm{I}_{\mathrm{in}}+\mathrm{I}_{\mathrm{Lr}, \mathrm{p}}
\end{array}
$$

Mode $5\left[\mathrm{t}_{4}-\mathrm{t}_{5}\right]$ The resonance stops when the $\mathrm{S}_{2}$ body diode turns off, at $t_{4}$. This mode is similar to the input inductor charging mode of conventional boost converter.

Mode $6\left[\mathrm{t}_{5}-\mathrm{t}_{6}\right]$ By turning off the $\mathrm{S}_{3}, \mathrm{~V}_{\mathrm{cs} 3}$ which is equal to switch voltage, linearly charges by $\mathrm{I}_{\mathrm{in} 2}$. So the $\mathrm{S}_{3}$ is turned off under $\mathrm{ZV}$ condition.

$$
\mathrm{V}_{\mathrm{cs} 3}=\frac{\left(\mathrm{t}_{6}-\mathrm{t}_{5}\right)}{\mathrm{C}_{\mathrm{s} 3}} \mathrm{I}_{\mathrm{in} 2}
$$

Mode $7\left[\mathrm{t}_{6}-\mathrm{t}_{7}\right]$ When $\mathrm{V}_{\mathrm{cs} 3}$ reaches to the $\mathrm{V}_{\mathrm{o}}-\mathrm{V}_{\mathrm{cr}, \mathrm{p}}$, $\mathrm{D}_{2}$ is turned on under ZVS condition. This mode continues until $\mathrm{C}_{\mathrm{r} 2}$ is completely discharged and $\mathrm{C}_{\mathrm{s} 3}$ and $\mathrm{C}_{\mathrm{r} 1}$ are charged to reach $\mathrm{V}_{\mathrm{O}}$.

Mode $8\left[\mathrm{t}_{7}-\mathrm{t}_{8}\right] \mathrm{D}_{3}$ turns on at $\mathrm{t}_{7}$. Then $\mathrm{I}_{\text {in2 }}$ flows through $\mathrm{D}_{3}$ to the output and $\mathrm{D}_{2}$ turns off under $\mathrm{ZV}$ condition.

Mode 9 [ $\left.\mathrm{t}_{8}-\mathrm{t}_{9}\right]$ By turning off the $\mathrm{S}_{1}, \mathrm{~V}_{\mathrm{cs} 1}$ which is equal to switch voltage, linearly charges by $\mathrm{I}_{\text {in } 1}$. This mode continues to discharge $\mathrm{C}_{\mathrm{r} 1}$.

Mode $10\left[t_{9}-t_{10}\right]$ This mode is started by turning on $\mathrm{D}_{1}$. It is similar to the power transfer state in the conventional boost converter. This mode last until the next switching cycle.

\section{SIMULATION RESULTS}

The proposed multi input converter has designed based on previous section and for following conditions. Input voltage $\mathrm{V}_{\text {in } 1}=50 \mathrm{~V}_{\mathrm{DC}}, \mathrm{V}_{\text {in2 }}=100 \mathrm{~V}_{\mathrm{DC}}$, output power $=300$ Watt, output voltage $=200 \mathrm{~V}_{\mathrm{DC}}$ and the switching frequency is $100 \mathrm{KHz}$

Based on above specifications, the following circuit elements values are selected as $\mathrm{L}_{\mathrm{r}}=5 \mathrm{uH}$, $\mathrm{L}_{\mathrm{m} 1}=\mathrm{L}_{\mathrm{m} 2}=1 \mathrm{mH}, \quad \mathrm{C}_{\mathrm{r} 1}=\mathrm{C}_{\mathrm{r} 2}=15 \mathrm{nF}, \quad \mathrm{C}_{\mathrm{s} 1}=\mathrm{C}_{\mathrm{s} 2}=1 \mathrm{nF} \quad$ and 
$\mathrm{C}_{\mathrm{o}}=100 \mathrm{uF}$. Then the proposed converter is simulated
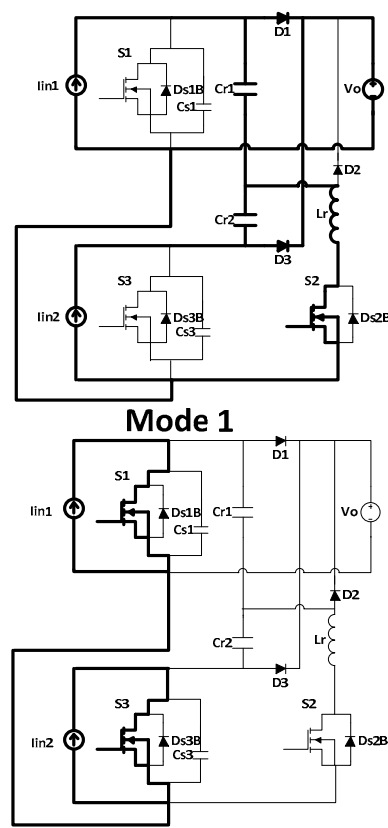

Mode 5

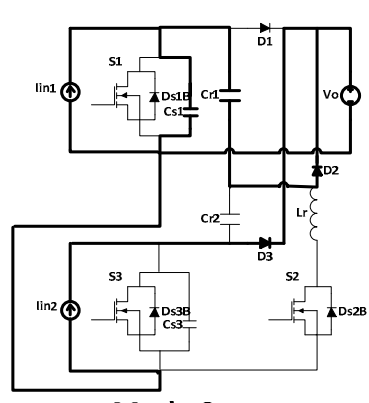

Mode 9

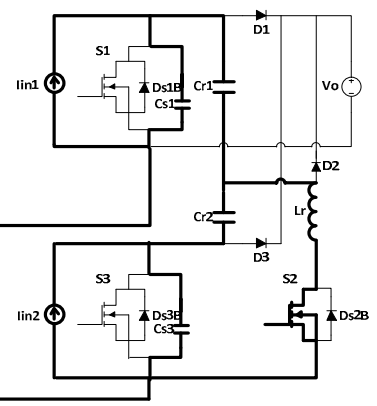

Mode 2

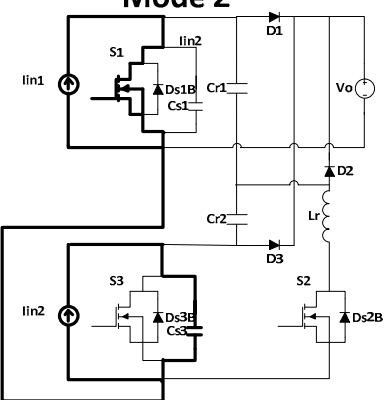

Mode 6

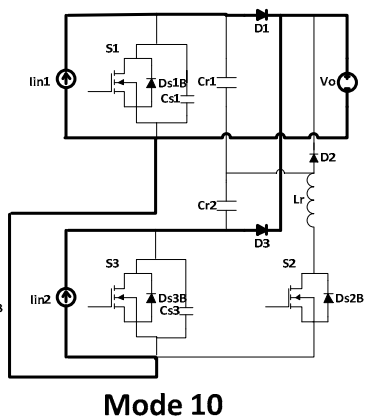

Mode 10

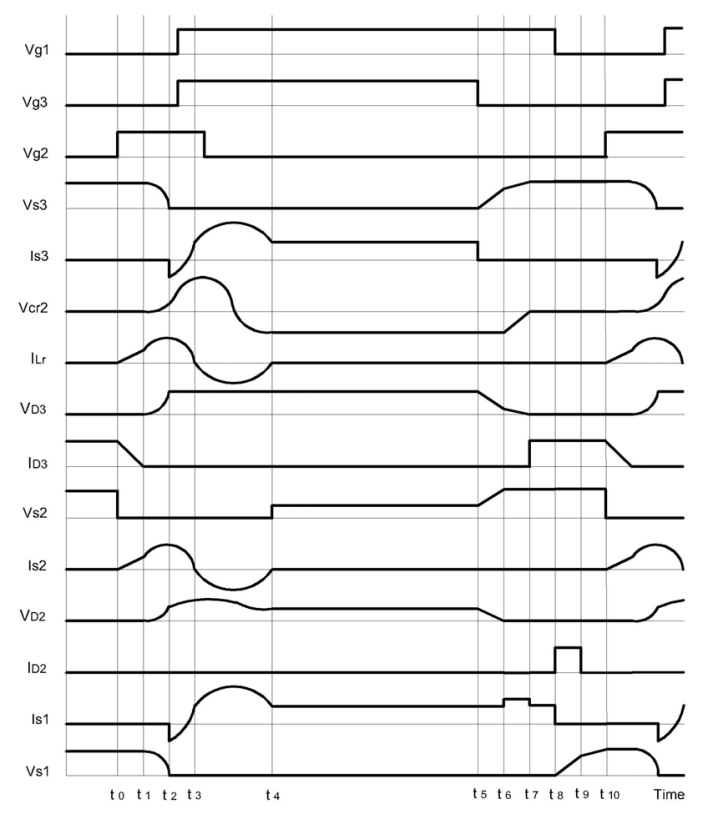

Figure 3. key waveform of the proposed converte

Simulated waveforms are shown in Fig. 4-5. In all of the simulation results, the continuous lines are by ORCAD.
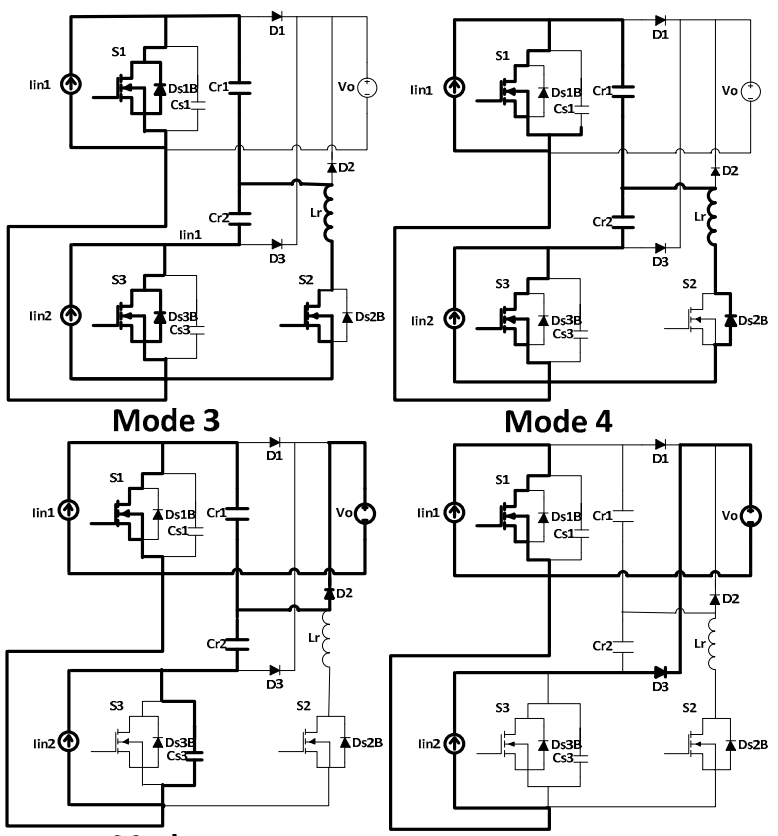

Mode 7

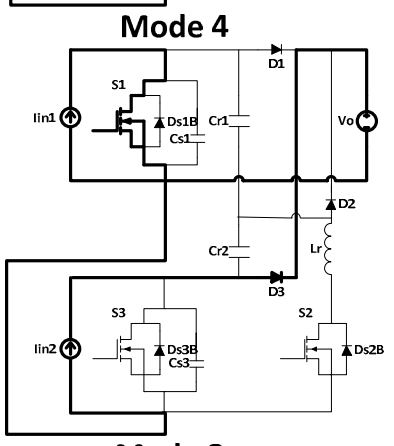

Mode 8

voltage and the discrete lines are current. Fig. 4(a) shows that the main switches turn off and on under zero voltage. Also ZVS of main diode can be seen in fig. 4(b). fig. 5(a) shows the auxiliary switch turn off under ZVZCS and turn on under ZCS condition. This figure shows that the auxiliary switch can turn on near ZCS because of the discharge of the parasitic drainsource capacitor. Soft switching of the auxiliary diode $\mathrm{D}_{2}$ is shown in fig. 5(b). This figure shows the diode switching is under ZVS condition.

Fig. 6 shows the efficiency comparison of the proposed converter and dual input hard switching boost converter. This curve is plotted by simulation results of the ORCAD. Continuous line shows the efficiency of the proposed converter and discrete line shows the efficiency of the hard switching counterpart. This figure shows 1 percent improvement in efficiency of proposed converter in comparison with hard switching counterpart.

\section{CONCLUSION}

In this paper, the proposed dual input ZVS converter theoretically is analyzed. And various operating mode and simulation results are investigated. Simulation results show that the proposed technique can have one percent improvement in the efficiency of the converter at the nominal load. In addition, due to using of the ZVT technique, EMI noise has decreased significantly because $\mathrm{dv} / \mathrm{dt}$ has been decreased. The simulation result confirms the theoretical analysis of operation. It must be noted that, the control of this converter is PWM. And the number of required switches to provide the soft switching condition is just one switch and it can be easily improved to multi inputs. The diode reverse-recovery is solved by providing ZVS condition for main diode. The proposed converter is providing soft switching conditions with one auxiliary circuit for all semiconductor elements. Suggested idea 
can easily expanded for more boost converter that is one of the strong points of this technique.

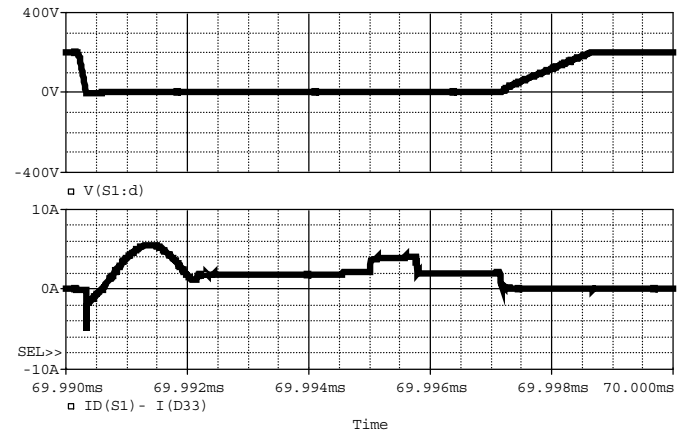

( a )

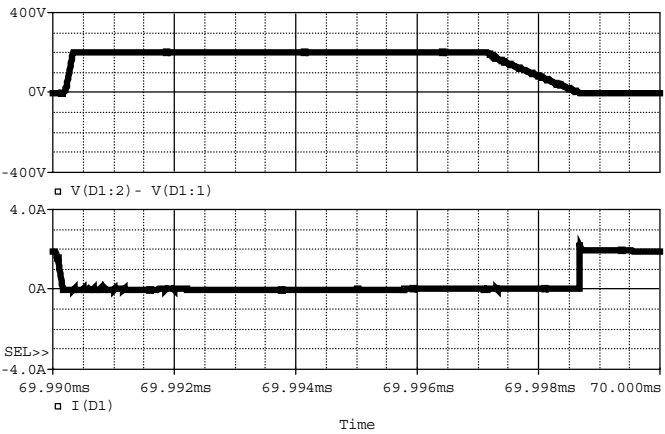

( b )

Figure 4. (a)voltage and current waveform of the main switch (b)voltage and current waveform main diode
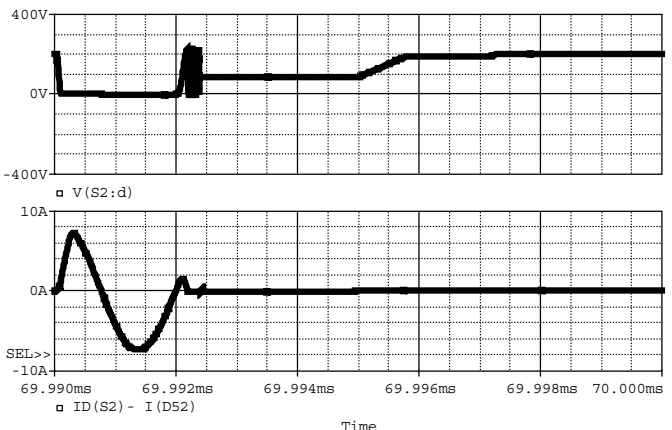

( a )

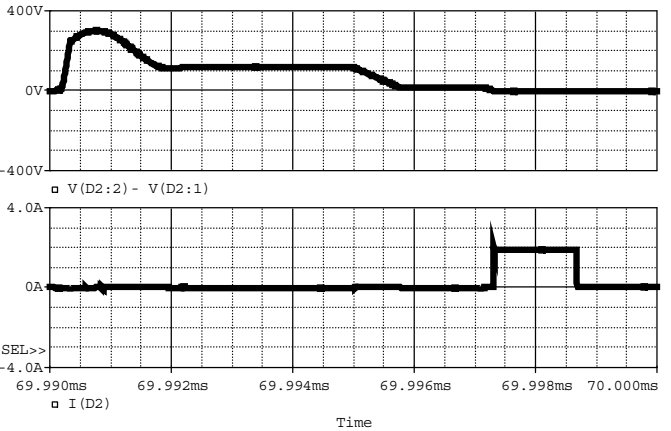

( b )

Figure 5. (a)voltage and current waveform of the auxiliary switch (b)voltage and current waveform auxiliary diode

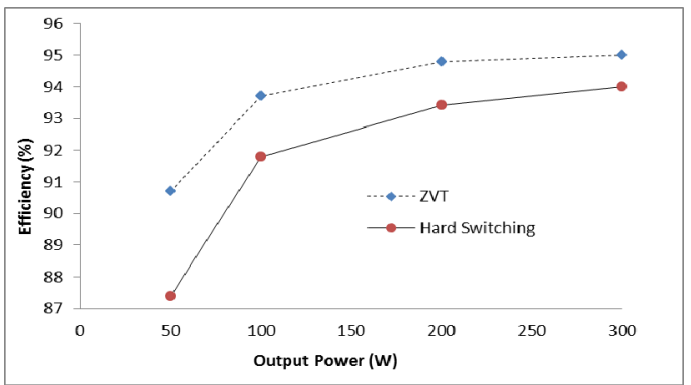

Figure 6. Efficiency comparison of the proposed converter and dual input hard switching boost converter

\section{REFERENCES}

[1] H. Xu, J. Xu, Z You, W. Peng, K Zhang and J.Xu,"Thermal Simulation of Traction System for High-Speed Train Based on Heat Accumulation," Journal of Computers, vol. 7, no. 4, pp. 1034-1040, Apr.. 2012.

[2] X. Li, Q. Pan and K. He, "Modeling and Analysis of Harmonic in the Mine Hoist Converter Based on Double Closed-Loop Control," Journal of Computers, vol. 7, no.6, pp. 1353-1360, Jun. 2012

[3] Q. Li, "A Fully-Integrated Buck Converter Design and Implementation for On-Chip Power Supplies," Journal of Computers, vol. 7, no. 5, pp. 1270-1277, May. 2012.

[4] S. Danyali, S. H. Hosseini, " New Extendable Sinngle-Stage Multi-Input DC-DC/AC Boost Converter", in IEEE Travs. Ind. Electron., 2014, PP. 775-788.

[5] H. Tao, A. Kotsopoulos, J. L. Duarte, and M. A. M. Hendrix, "Multiinput bidirectional dc-dc converter combining dc-link and magneticcoupling for fuel cell systems," in Industry Applications Conference, 2005. Fourtieth 1AS Annual Meeting. Conference Record of the 2005, vol. 3, 2005, pp. 2021-2028 Vol. 3.
[6] Y. Yuan-mao and K. W. E. Cheng, "Multi-input voltagesummation converter based on switched-capacitor," Power Electronics, 1ET, vol. 6, no.9,pp.1909-1916,2013.

[7] J. Wei and B. Fahimi, "Multiport power electronic interface;concept, modeling, and design," Power Electronics, IEEE Transactions on, vol. 26,no. 7,pp. 1890-1900,2011.

[8] T. Haimin, J. L. Duarte, and M. A. M. Hendrix, "Three-port triplehaif: bridge bidirectional converter with zero-voltage switching," Power Electronics, IEEE Transactions on, vol. 23, no. 2, pp. 782-792,2008.

[9] Yuanbin Li, Peng Ge and Ben Niu "Research on a Novel Soft-Switching Buck Converter, " Research Journal of Applied Sciences, Engineering and Technology vol. 18, no. 5, pp. 4510-4517, May 2013.

[10] E. Adib H. Farzanehfard, "Family of zero current zero voltage transition PWM converters," IET Power Electron (IREE)., Vol. 1,no. 2, pp. 214-223, 2008.

[11] S.H. Park,G.R. Cha, Y.C. Jung and C.Y. Won, "Design and application for PV generation system using a soft switching boost converter with SARC," IEEE Trans. On Industrial Electronics, vol. 57, no. 2, pp515-522, 2010.

[12] J. G. Kassakian, M. F. Schlecht, and G. C. Verghese, "Principles of Power Electronics," Reading,MA: AddisonWesley, 1991.

[13] Rong-Jong Wai, Senior Member, IEEE, Chung-You Lin, JunJie Liaw, and Yung-Ruei Chang, Member, IEEE'Newly Designed ZVS Multi-Input Converter'IEEE TRANSACTIONS ON INDUSTRIAL ELECTRONICS, VOL. 58, NO. 2, FEBRUARY 2011.

[14] P. Devender and, G. Parvathi ‘ A ZVS Dual-Input Converter With Hybrid Power Surces' M.Tech(Pursuing) and 2 Assistant Professor 1 2, Vaagdevi College of ngineering Autonomous), Bollikuntta, Warangal, Proceedings of International Conference on Emerging Trends in Engineering \& Technology (ICETET-2014) 29th - 30th September. 